\title{
INVESTIGATING ADOLESCENTS' PERCEPTIONS REGARDING RURAL TOURISM, AN ALTERNATIVE FORM OF TOURISTIC REINFORCEMENT FOR THE GREEK COUNTRYSIDE
}

\author{
I. POLITIS ${ }^{1} \&$ M. CHATZIGEORGIOU ${ }^{2}$ \\ ${ }^{1}$ Model Experimental Lyceum of the Ionideio School in Piraeus, Greece. \\ ${ }^{2}$ Zanneio Model Experimental High School of Piraeus, Greece.
}

\section{ABSTRACT}

In this field research, we investigate the views and life attitudes that children between 13 and 16 years of age adopt towards rural tourism and the main characteristics of the vacation model they ideally prefer and/or choose to pursue. This study further aims to constitute an educational guide for an innovative environmental programme of actions in order to sensitize even students with no active environmental spirit. The present applied sampling research involved the completion of a brief questionnaire by 413 sample students from Greek secondary education schools (day high schools and lyceums) of the Attica, Ilia, Arkadia and Evros prefectures. The reliability of the questionnaire as a research tool was reinforced by the fact that all respondents were asked to answer the same questions. The analysis of variance method was used to identify the differences. It has become clear that the majority of secondary education students are fond of nature and they support the sustainable management of the environment; yet, there is a significant percentage of adolescents who are not familiar with rural tourism as an alternative model of tourism. The results generate an added value to rural tourism education and eco-feminist theories.

Keywords: Students' perceptions, secondary education, rural tourism, environmental education, vacation.

\section{INTRODUCTION}

Mountains are integral and important parts of the climate system [1]. Meteorological factors such as solar radiation, air temperature and humidity, in combination with the intense relief, different slopes, orientations and other topographic irregularities, result in a variety of microclimates in mountain areas [2-6]. In general, mountains are among the most popular destinations for tourists that represent unique regions for the detection of climate change and the assessment of climate-related impacts [7]. The air temperature, with fluctuations which are greater during spring and autumn [8-10], is the most important component influencing the mountainous climate, and it regulates a broad range of ecosystem processes [11].

Unfortunately, Greece is the one country in Europe that does not have a strategy for developing the mountainous regions. These development measures should be consequent to the remaining rural community and to recent country dwellers, who would like to recolonize the mountainous areas on account of the continuing degradation of the quality of life in urban areas or due to climate change [12]. As with most similar areas around the world, the Greek mountainous regions come up against certain problems that focus mostly on their neglect and desolation, aging population, financial decline, land disintegration, short blooming period, extreme but not uncommon, unpredictable weather conditions, intense variations in elevation, and lack of infrastructure such as hospitals, schools, etc. [13-16].

A certain development model for mountain areas considers the stimulation of more moderate and alternative forms of tourism such as rural tourism, which has enjoyed remarkable development in 
rural areas for two main reasons: Firstly, the citizens of urban and industrial areas need to be close to nature and relax in a tranquil place. Secondly, the population of mountainous areas seeks a complementary income, which does not preclude agricultural activities [17]. In contrast to urban regions, mountainous forest areas, in general, seem to be more suitable for residents and tourists. According to Barradas [18], through transpiration plants release water vapour to the surroundings, increasing the humidity and decreasing the temperature. Therefore, mountainous forest areas are characterized by more favourable environmental conditions compared with urban areas in the warmer months of the year [19-23]. Nowadays, forms of specific rural tourism, with strong environmental emphases, have become increasingly popular and more attractive especially to people who were born in the countryside, but live in the cities [24].

In the present study we aim to investigate the perceptions of Greek secondary education students, who attend day high schools (13-15 years old) and lyceums (16-18 years old), regarding the different aspects of rural tourism. The main interest focused on its impact both on the environment, with a view to fewer burdensome effects, as well as on the plans to improve the infrastructure improvement plans, given that rural tourism could operate like an antidote to the financial decline, from which the Greek countryside has been suffering over recent decades. To achieve this purpose, research was carried out by distributing a questionnaire to students between 13 and 16 years of age in four Greek prefectures. The present study further aims to constitute an educational guide for an innovative environmental programme of actions.

\section{MATERIALS AND METHODS}

\subsection{Setting goals}

Through questionnaires, the present field research aims at investigating the views and life attitudes that children between 13 and 16 years of age adopt towards rural tourism and the main characteristics of the vacation model that they ideally prefer and/or choose to pursue. Specifically, this research aims at the following goals that students: (a) become acquainted with rural tourism as an alternative form of tourism, (b) maintain contact with the mountain environment and rural populations of Greece, (c) become familiar with occupations and activities, which the inhabitants of those mountainous destinations used to be involved, in the past, or still at present maintain, (d) appreciate the forest's ecological significance and contribution which is inextricably linked with local populations, (e) become informed about ways of protecting forest ecosystems, (f) gradually become motivated citizens who are eager to undertake actions for the sustainable management of their own home place through the prominence and the support of both local culture and cultural heritage and $(\mathrm{g})$ combine in full practice the concept of the environment with that of culture and investigate the parameters that determine this twofold system.

\subsubsection{Study methods}

This study chose to apply random sampling techniques for assessment. Sampling methods in qualitative and quantitative research are the most suitable and most popular practices for collecting primary data throughout the sociology research field. These methods constituted the principal procedures for the collection and elaboration of research data in order to seek answers for the various problems that arose [25]. The present applied sampling research involved the completion of a brief questionnaire, which is considered more suitable for collecting data in comparison with the personal interview, due to the specific advantages it provides. The questionnaire offers the possibility for 
many people to participate, forming a large sample, the reassurance of anonymity, the assurance of objectivity and impartiality, and it facilitates simultaneous distribution at many points $[25,26]$. The reliability of the questionnaire as a research tool was reinforced by the fact that all respondents were asked to answer the same questions. All the volunteers who participated answered the same number of questions. Because nowadays the Summated Rating Likert Scale (1932) is the most widespread scale type for measuring the attitudes, beliefs and aspects of large groups of people, in this questionnaire, three questions of this kind were introduced among others (Fig. 1). Such an approach relies on the acknowledgement that a person's total score on this scale is evident of their attitude towards the specific matter. The answers to those above-mentioned three questions were given in the form of a five-choice scale that implies a gradient, or rather, a differentiated level of agreement or disagreement with the proposal posed by the question [27]. All answers were introduced into tables so that their statistical processing might be followed with the aid of the MS Excel and SPSS v.19.0 statistical analysis tools, whereas the significance levels were $\mathrm{p}<0.05$ and $\mathrm{p}<0.01$, respectively. The statistical analysis procedures include descriptive statistics techniques for the determination of frequency and percentages and the production of suitable charts. Finally, as far as the questionnaire is

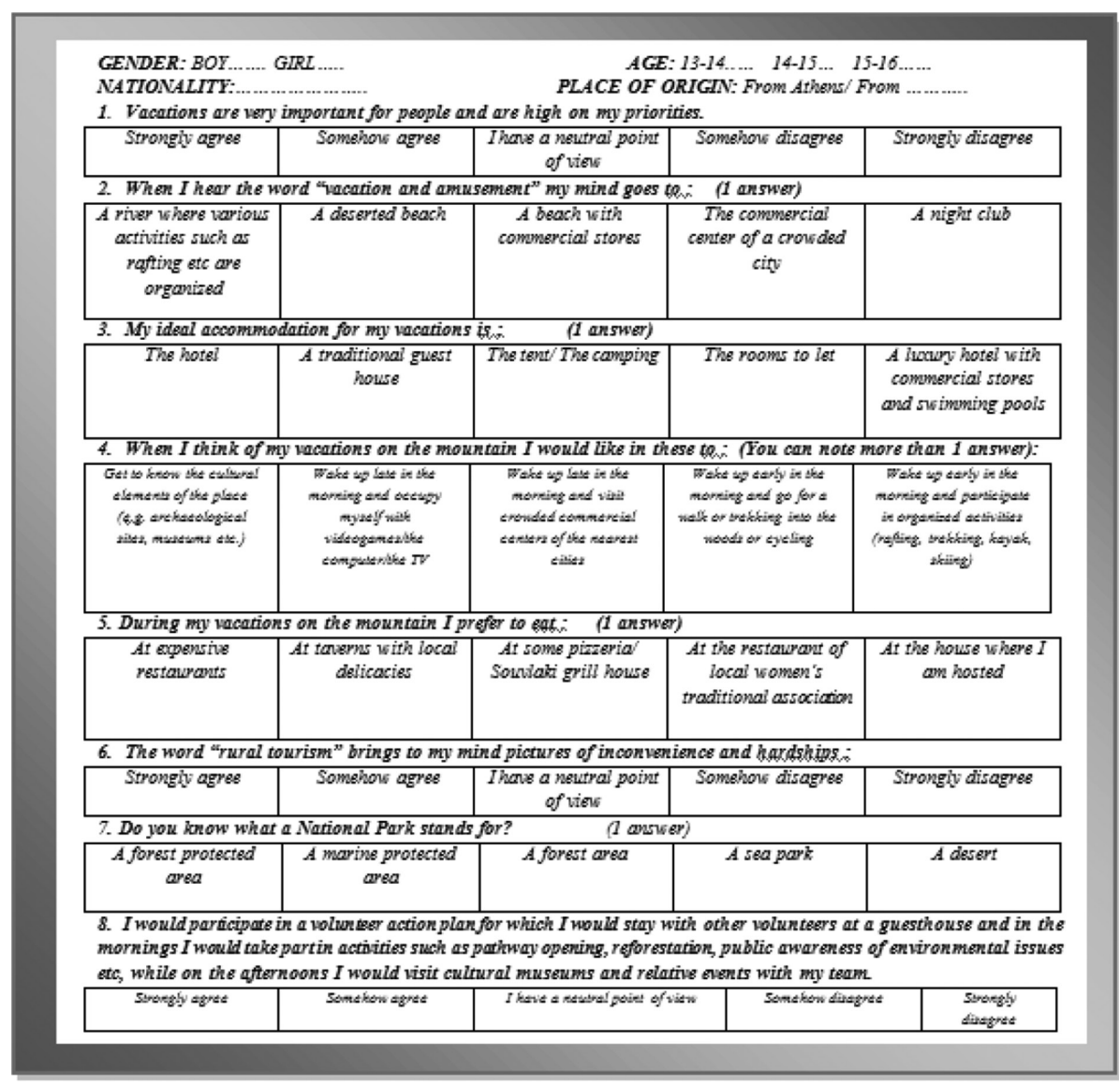

Figure 1: The questionnaire that was distributed to the students who participated in the research. 
concerned, a variable correlation control was firstly implemented with the independence test (Chisquare test) and the Pearson's Chi-square was determined.

Then, a series of Chi-square tests were performed to compare preferences on definitional elements of the survey questionnaire on Questions 2, 3, 5 and 7, whereas one-way analysis of variance (ANOVA) was used to contrast levels of agreement on the answers to Questions 1, 6 and 8 across the gender, the age and the origin of the respondents $(\mathrm{p}<0.05)$. Post hoc pair-wise comparisons were then conducted with any significant ANOVA (Tukey's test) and Chi-square results [28,29]. Research by questionnaires consists of a detection means, which is useful for studies that implicate easily determined and diachronically comparative parameters [30,31]. The questionnaire completion time was 5-6 min and was enough for the sample students to complete all the questions posed without losing at the same time any interest of the procedure [32]. The questionnaire was original and comprised four general closed-type questions in relation to the demographic data of the volunteer student (such as gender, age, nationality, place of origin) and eight specific and focused closed-type questions (with the possibility, in one of them, of selecting more than one given answer), which best served the scopes of the study.

Furthermore, the study took place within the period of October to November 2013, and 413 sample students from Greek secondary-education schools (day high schools and lyceums) in the Attica, Ilea, Arkadia and Evros prefectures participated (Fig. 2). The distribution and completion of the questionnaire did not take place in all cases with the parallel presence of the researchers. The choice of schools and student potential were made at random in order to achieve maximum reliability as far as the study results are concerned.

\section{RESULTS AND DISCUSSION}

As regards the nationality of this study's participants, the overwhelming majority of them were Greek students, $97.1 \%$ of those in Athens' schools and $100 \%$ of those in rural schools were of Greek nationality. For the rest of the demographic data, the capital's student population is heterogeneous in

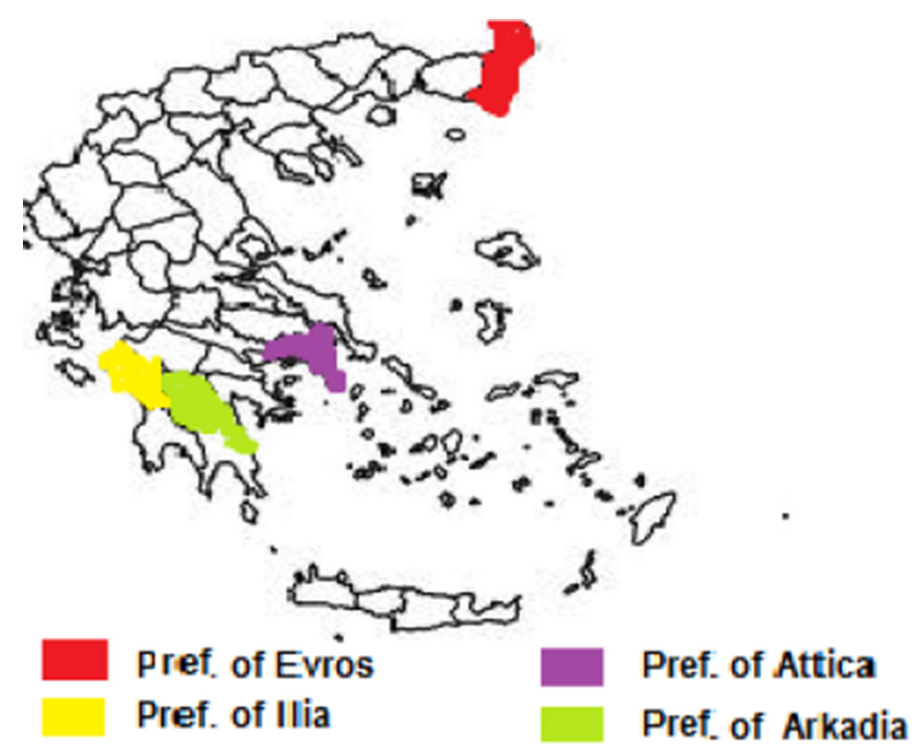

Figure 2: Map of Greece. The coloured prefectures represent the study area. 
terms of the origin and provenance (Athens $77.7 \%$, Abroad 1.6\%, Periphery 20.7\%) in relation to the population in the provinces (Athens 1\%, local population 99\%), which is more homogeneous.

Questions 1,2, and 3 deal with students' perceptions about the priority that the constitution of vacation has in their lives and the place they view as suitable for them to rest and lodge at. In Question 1, the majority of the respondents, both in the capital (71.6\%) and the country (55.3\%), place vacations high in their priorities. The percentage is higher among Athenian students, due to their more persistent need to escape from the intensively structured and densely inhabited fabric of the urban place in which they live, rather than among their provincial colleagues [24]. In Question 2, alternative tourism in mountains shows a rather low percentage in their preferences, whereas vacations close to a river's springs and tributaries are preferred approximately $7 \%$ more by those students who live in the countryside, because they are more familiar with this form of tourism (Fig. 3).

In Question 3, it is obvious that the majority of students (33.3\% from the capital and 31.1\% from the provinces) chose a luxury hotel with extensive facilities and amenities as ideal accommodation. According to their preferences, the traditional guesthouse follows for city dwellers but for those from the provinces, the choice of a common hotel still remains at second place.

Question 4 relates to the activities that teenagers would like to engage in when on vacation in the mountains, an issue that deserves further investigation in order to draw safer conclusions.

Question 5 deals with the type of food that the respondent teenagers are invited to select when they are on vacation in a certain mountainous destination. The majority of students ( $60 \%)$ chose to taste traditional gastronomy dishes of the local region, whereas high in students' demand ( 16\%) remained pizza and souvlaki, foods not at all insignificant for this particular age group of participants in the present research. Moreover, teenage respondents from the provinces are more familiar with the institution of women's traditional cooperatives at approximately $10 \%$.

Questions 6 and 7 deal with how students effectively comprehend the concepts of rural tourism and that of the institution of a National Park. Considering all the students that took part in this research at high levels $(23.3 \%)$ remains that group of adolescents who presented themselves doubtful about the conditions that entrench people's relationship with rural tourism. In Question 7, the vast majority of students in both the capital (71.9\%) and the provinces (69.9\%), appear to understand, at least theoretically, the concept of the term 'National Park', due to the subjects of the educational curricula.

The questionnaire closes with the eighth and final question, which relates to the possible participation (or not) of the surveyed students in volunteer plans with action teams. It becomes clear that the majority of the respondents from both the capital (62.3\%) and the provinces (64.1\%) agreed to

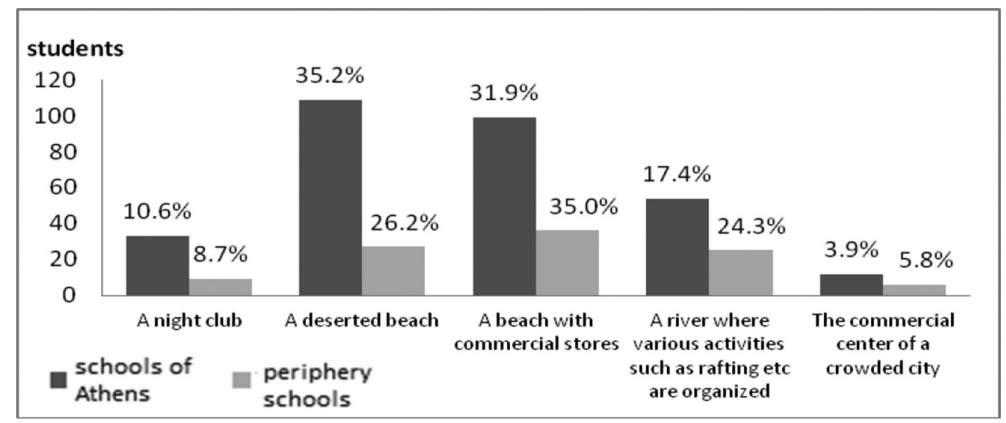

Figure 3: The percentage distribution of responses to Question 2 of the questionnaire, distributed to secondary education students. 
take part in voluntary actions that focus on and aim at the protection and sustainable management of the environment. Nevertheless, there is a large percentage, $36 \%-38 \%$ of the students, not willing to participate voluntarily in any environmental and/or cultural action and face this issue with scepticism.

To examine Questions 2, 3, 5 and 7 (as variables) in relation to the variables 'gender', 'age' and 'origin', their statistical processing was considered necessary with the performance of the independence test (Chi-square test) as a tool, in order to compare preferences on the substantial elements of the survey questionnaire. The analysis of the results through the Pearson's Chi-square method revealed that there is a statistical correlation of a high significance level $(p<0.001)$ between the respondents' gender and origin and the answers which they chose in the above-mentioned questions (Table 1). Indeed, more girls than boys prefer beaches with commercial stores, the luxury hotel, restaurants with local dishes [28], correctly understand the concept of the term 'National Park' and ignore the content of rural tourism.

There is no statistical correlation between students' age and the responses provided, except for the case of Question 7, where at this certain point age did play an important role in the participants correctly recognizing the definition of 'National Park'.

Subsequently, in order to examine Questions 1, 6 and 8 (as variables) with regard to the variables 'gender', 'age' and 'origin' for their statistical processing, one way ANOVA was used to contrast levels of agreement on the answers to the above questions (Table 2).

Table 1: Comparison of the response frequency in relation to the gender, age and origin of the volunteer students.

\begin{tabular}{lllll}
\hline & Quest. 2 & Quest. 3 & Quest. 5 & Quest. 7 \\
\hline Gender & $170.849^{*}$ & $168.725^{*}$ & $421.536^{*}$ & $279.659^{*}$ \\
Age & 18.359 & 13.145 & 14.437 & $40.234^{*}$ \\
Origin & $176.847^{*}$ & $182.082^{*}$ & $427.678^{*}$ & $289.576^{*}$ \\
\hline
\end{tabular}

The numbers denote the value of the Pearson's Chi-square coefficient for each pair of variables.

*Indicates significance at level $\mathrm{p}<0.001$, whereas the absence of asterisks implies a corresponding lack of significance.

Table 2: Comparison of the levels of agreement between the responses of the survey's respondents in contrast to the gender, age and origin variables.

\begin{tabular}{llll}
\hline & Quest. 1 & Quest. 6 & Quest. 8 \\
\hline Gender & 0.048 & 0.132 & $12.962^{\#}$ \\
Age & 1.756 & $3.435^{*}$ & 0.998 \\
Origin & 2.190 & 1.176 & 2.383 \\
\hline
\end{tabular}

The numbers denote the value of the $\mathrm{F}$ coefficient for each pair of variables in the one-way analysis of variance.

*Indicates significance at level $\mathrm{p}<0.05$, \#indicates significance at level $\mathrm{p}<0.001$, whereas the absence of asterisks implies a corresponding lack of significance. 
The results make explicit that there is a high statistical difference between the variables 'gender and Question 8', which indicates that at approximately 67\% girls are more eager to enter an environmental volunteering plan than boys who follow at a percentage of approximately $56 \%$ [28]. A similar statistically significant difference is observed between the variables 'age and Question 6', which is confirmed by further statistical processing with the post hoc test, selecting the Tukey's method. After application, the results are consistent with those of ANOVA. These statistics lead to possible conclusions that the age factor plays an important role in adolescent decision making, as far as the mean agreement about what kind of tourism rural tourism advocates, is concerned.

\section{CONCLUSIONS}

Although some European countries, such as France, Switzerland, Germany, Austria, Sweden and Hungary, have a long-standing tradition of rural tourism development [33], Greece faces the lack of strategy for development in mountainous areas. It has become clear throughout the whole study that the majority of secondary education students are fond of nature and they support the sustainable management of the environment. However, there is a significant percentage of adolescents who are not familiar with rural tourism as an alternative model of tourism. This alternative model is equally attractive and useful both to themselves, because it satisfies the demand for peaceful and economical holidays close to nature and the local community, and to the rural regions, since it functions as a lever for retaining population, helping to avoid the financial decline of the countryside and exploiting to the maximum the natural, cultural and historic resources of the area [34]. At the same time, all local bodies (rural cooperatives and local authorities) are encouraged to activate and coordinate their mechanisms in a constant search for the promotion of development in the region [35] throughout the whole year by constructing little guest houses and paths through the woods, which promote local products, while a parallel utilization of the landscape takes place [36,37].

The latest international and internal social and financial circumstances progressively influence the configuring of adolescents' choices in specific directions. A fair percentage seeks all the comfort and luxury that has gradually been eclipsed from the daily lives of adolescents, while, at another percentage, teenagers appear to be prompted by their surroundings amongst a range of reasons more sensitized to find more economical and cost-effective solutions.

The question is how the Greek school and its educational system will manage, on one hand, to sensitize and enhance the development of that group of students who do not present an active environmental spirit, being totally indifferent towards such causes, and on the other hand, how to rekindle the flame and enthusiasm of those young people who show great interest and true problematization regarding the sustainable and viable management of the environment.

Beyond its planned objectives, the present research can also constitute an Educational Act guide in terms of an innovative environmental education programme. Students can plan the structure and eventually construct their own questionnaire, from the application of which, they will later draw conclusions that relate to their particular place of residence or of origin. Maximum emphasis, with the aid of appropriate activities/worksheets, should be placed on informing and familiarizing all students with the concepts of rural tourism through their contact with areas of Greece that have begun to develop this more moderate form of tourism. Additionally, in this way, the meaning and nature of processing, investigating and problem solving are cultivated throughout a valid and scientific rationale, which strongly presents the basis for ensuring the continuity of the production of scientific data and conclusions in the future, as far as tourism and environmental research are concerned. 


\section{ACKNOWLEDGEMENTS}

The authors wish to extend their most sincere appreciation to Mr. C. Bentis, Mr. S. Sotiropoulos, Mrs. C. Georgopoulou, Mrs. C. Arathymou, Mrs. J. Aggeletou and Mrs. M. Galanopoulou for their kind support, cooperation and overall help to fulfil this study.

\section{REFERENCES}

[1] Beniston, M., Climatic change in mountain regions: a review of possible impacts. Climate Change, 59, pp. 5-31, 2003. doi: http://dx.doi.org/10.1007/978-94-015-1252-7_2

[2] Barry, L.G., Mountain Weather and Climate, 2nd edn., Routledge, Taylor and Francis Group: New York, USA, p. 189, 2001.

[3] Kamoutsis, A., Matsoukis, A., Manoli, E. \& Chronopoulos, K., An artificial neural network model application for the estimation of thermal comfort conditions in mountainous regions, Greece. Atmosfera, 25(2), pp. 171-181, 2012.

[4] Flokas, A., Courses of Meteorology and Climatology, Ziti: Thessaloniki, Greece, p. 465, 1997.

[5] Geiger, R., Climate Near the Ground, Harvard University Press: Cambridge, USA, p. 482, 1950.

[6] Chronopoulos, K., Kamoutsis, A. \& Matsoukis, A., Thermal comfort estimation in relation to different orientation in mountainous regions in Greece by using artificial neural networks. Global NEST Journal, 14(4), pp. 532-539, 2012.

[7] Gobiet, A., Kotlarski, S., Beniston, M., Heinrich, G., Rajczak, J. \& Stoffel M., 21st century climate change in the European Alps-A review. Science of the Total Environment, 493, pp. 1138-1151, 2014. doi: http://dx.doi.org/10.1016/j.scitotenv.2013.07.050

[8] Bolstad, P., Swift, L., Collins, F. \& Regniere, J., Measured and predicted air temperatures at basin to regional scales in the southern Appalachian mountains. Agricultural and Forest Meteorology, 91, pp. 161-176, 1998. doi: http://dx.doi.org/10.1016/s0168-1923(98)00076-8

[9] Koutsogiannis, D. \& Xanthopoulos, Th., Technical Hydrology (in Greek), 3rd edn., National Technical University of Athens: Greece, p. 418, 1999.

[10] Chronopoulou-Sereli, A. \& Flokas, A., Courses of Agricultural Meteorology and Climatology (in Greek), Ziti: Thessaloniki, Greece, p. 557, 2010.

[11] Dobrowski, S., Abatzoglou, J., Greenberg, J. \& Schladow, S., How much influence does landscape-scale physiography have on air temperature in a mountain environment? Agricultural and Forest Meteorology, 149, pp. 1751-1758, 2009. doi: http://dx.doi.org/10.1016/j. agrformet.2009.06.006

[12] Tsipiras, K., Mountainous Greece and its nature as a "whole" (in Greek). Presented at the 3rd Interdisciplinary and Interuniversity Conference of N.T.U.A. and Metsovion Interdisciplinary Research Centre (M.I.R.C.) of the N.T.U.A., Metsovo, Greece, 2001.

[13] Jansky, L., Ives, J., Furuyashiki, K. \& Watanabe, T., Global mountain research for sustainable development. Global Environmental Change, 12, pp. 231-239, 2002. doi: http://dx.doi. org/10.1016/s0959-3780(02)00015-8

[14] Papadimatou, A. \& Rokos, D., "Sustainable" and worth-living integrated development of mountainous areas in Greece and worldwide (in Greek). Proceedings of the 3rd Interdisciplinary and Interuniversity Conference of N.T.U.A and Metsovion Interdisciplinary Research Centre (M.I.R.C.) of the N.T.U.A., Metsovo, Greece, 2004.

[15] Michailidou, E., Mountainous areas of Greece. Characteristics and development strategies (in Greek). Presented at the 6th Interdisciplinary and Interuniversity of N.T.U.A. and Metsovion Interdisciplinary Research Centre (M.I.R.C.) of the N.T.U.A., Metsovo, Greece, 2008. 
[16] Rokos, D., The integrated development of mountainous areas. Theory and practice (in Greek). Proceedings of the 3rd Interdisciplinary and Interuniversity Conference of N.T.U.A. and Metsovion Interdisciplinary Research Centre (M.I.R.C.) of the N.T.U.A., Metsovo, Greece, 2004.

[17] Panagiotou, I., The development of mountainous Nafpaktia area, MSc Thesis (in Greek with English abstract), Harokopio University of Athens, Greece, 2007.

[18] Barradas, V.L., Air temperature and humidity and human comfort index of some city parks of Mexico City. International Journal of Biometeorology, 35, pp. 24-28, 1991. doi: http://dx.doi. org/10.1007/bf01040959

[19] Matsoukis, A., Kamoutsis, A. \& Chronopoulou-Sereli, A., Air temperature and thermal comfort conditions in mountainous and urban regions. International Journal of Sustainable Development Planning, 4, pp. 357-363, 2009. doi: http://dx.doi.org/10.2495/sdp-v4-n4-357-363

[20] Matsoukis, A., Kamoutsis, A. \& Charalampopoulos, I., Evaluation of biometeorological conditions of mountain communities and urban centers in Greece. Proceedings of the 1st International Conference on Environmental Management, Engineering, Planning and Economics Skiathos, eds. A. Kungolos, K. Aravossis, A. Karagiannidis \& P. Samaras, Greece, June 24-28, pp. 1526-1530, 2007.

[21] Manoli, E., Investigation of bioclimatic conditions and perspectives of development in Gerania mountains, MSc Thesis (in Greek with English abstract), Department of Sciences, Agricultural University of Athens Greece, 2008.

[22] Kamoutsis, A., Matsoukis, A., Charalampopoulos, I. \& Chronopoulou-Sereli, A., Biometeorological conditions in mountainous communities and adjacent urban centre in Greece by the use of indices: the case study of mountainous Nafpaktia district. Proceedings of the 3rd International Workshop on Climate, Tourism and Recreation, Alexandroupolis, Greece, September 19-22, pp. 144-149, 2007.

[23] Tseliou, A., Tsiros, I., Lykoudis, S. \& Nikolopoulou, M., An evaluation of three biometeorological indices for human thermal comfort in urban outdoor areas under real climatic conditions. Building and Environment, 45, pp. 1346-1352, 2010. doi: http://dx.doi.org/10.1016/j. buildenv.2009.11.009

[24] Ratz, T., European Tourism (Chapters 11, 13), Kodolanyi Janos University College: Hungary, p. 121, 2004.

[25] Aptoglou, I., The development and the sustainable management of ecotourism in protected areas. The case study of Natura 2000, Elatia and Fraktou, districts in the Prefecture of Drama, MSc Thesis (in Greek with English abstract), Department of Sciences (Biology), University of Patra, Greece, 2007.

[26] Cohen, L. \& Manion, L., Methodology of Educational Research, trans. X. Mitsopoulou \& M. Filopoulou, Ekfrasi: Athens, 1997.

[27] Spector, P., Summated Rating Scale Construction. An Introduction, Quantitative Applications in the Social Sciences Series, Vol. 82, Sage Publications, Inc.: USA, 1992.

[28] Alonso-Almeida, M., Environmental management in tourism: students' perceptions and managerial practice in restaurants from a gender perspective. Journal of Cleaner Production, 60 , pp. 201-207, 2013. doi: http://dx.doi.org/10.1016/j.jclepro.2012.11.034

[29] Arroyo, C., Barbieri, C. \& Rozier Rich, S., Defining agritourism: a comparative study of stakeholders' perceptions in Missouri and North Carolina. Tourism Management, 37, pp. 39-47, 2013. doi: http://dx.doi.org/10.1016/j.tourman.2012.12.007

[30] Bell, J., Methodological Design of Pedagogical and Social Research: Instructions for Students and Candidates PhD (in Greek), Gutenberg: Athens, Greece, p. 251, 1999. 
[31] Kyriazi, N., The Social Research. Critical Review of the Methods and the Techniques (in Greek), Ellinika Grammata: Athens, Greece, p. 408, 1999.

[32] Pedagogical Psychological Encyclopedia Dictionary (in Greek), Vol. 4, pp. 2135-2136, Ellinika Grammata: Athens, Greece, 1989.

[33] Ratz, T. \& Puczko, L., Rural tourism and sustainable development in Hungary. Rural Tourism Management: Sustainable Options, International Conference, Conference Proceedings, eds. D. Hall \& L. O’Hanlon, Scottish Agricultural College, Auchincruive, Ayr, Scotland, UK, pp. 450-464, 1998.

[34] Flanigan, S., Blackstock, K. \& Hunter, C., Agritourism from the perspective of providers and visitors: a typology-based study. Tourism Management, 40, pp. 394-405, 2014. doi: http:// dx.doi.org/10.1016/j.tourman.2013.07.004

[35] Dudensing, R., Hughes, D. \& Shields, M., Perceptions of tourism promotion and business challenges: a survey-based comparison of tourism businesses and the promotion organizations. Tourism Management, 32, pp. 1453-1462, 2011. doi: http://dx.doi.org/10.1016/j.tourman.2010.10.008

[36] Charalampopoulos, I., Kamoutsis, A., Panagiotou, I. \& Chronopoulou-Sereli, A., Investigation of bioclimatic performance in specific mountain areas in Greece and evaluation for decision making in tourism development. Proceedings $(C D)$ in Human Biometeorology, Urban Climatology and Tourism, Environmental Agency of the Republic of Slovenia. Sixth Annual Meeting of the European Meteorological Society (EMS)/Sixth European Conference on Applied Climatology $(E C A C)$, ed. T. Cegnar, Ljubliana, Slovenia, 2007.

[37] Chatzigeorgiou, M., Microclimatic conditions of the mountainous Oxia complex in the Prefecture of Aitoloakarnania, MSc Thesis (in Greek with English abstract). Department of Sciences, Agricultural University of Athens Greece, 2013. 